\title{
Comparison of two extraction methods for evaluation of volatile constituents patterns in commercial whiskeys Elucidation of the main odour-active compounds
}

\author{
M. Caldeira, F. Rodrigues, R. Perestrelo, J.C. Marques, J.S. Câmara* \\ Centro de Química da Madeira, Departamento de Química da Universidade da Madeira, 9000-390 Funchal, Portugal \\ Received 8 March 2007; received in revised form 15 May 2007; accepted 18 May 2007 \\ Available online 24 May 2007
}

\begin{abstract}
An analytical procedure based on manual dynamic headspace solid-phase microextraction (HS-SPME) method and the conventional extraction method by liquid-liquid extraction (LLE), were compared for their effectiveness in the extraction and quantification of volatile compounds from commercial whiskey samples. Seven extraction solvents covering a wide range of polarities and two SPME fibres coatings, has been evaluated.

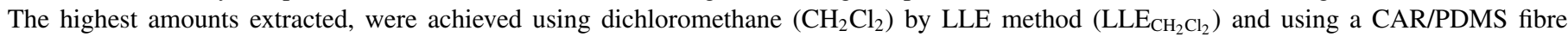
$\left(\mathrm{SPME}_{\mathrm{CAR} / \mathrm{PDMS}}\right)$ in HS-SPME. Each method was used to determine the responses of 25 analytes from whiskeys and calibration standards, in order to provide sensitivity comparisons between the two methods. Calibration curves were established in a synthetic whiskey and linear correlation coefficient $(r)$ were greater than 0.9929 for $\mathrm{LLE}_{\mathrm{CH}_{2} \mathrm{Cl}_{2}}$ and 0.9935 for $\mathrm{SPME}$ CAR/PDMS , for all target compounds. Recoveries greater than $80 \%$ were achieved. For most compounds, precision (expressed by relative standard deviation, R.S.D.) are very good, with R.S.D. values lower than 14.78\% for HS-SPME method and than $19.42 \%$ for LLE method. The detection limits ranged from 0.13 to $19.03 \mu \mathrm{g} \mathrm{L}^{-1}$ for SPME procedure and from 0.50 to $12.48 \mu \mathrm{g} \mathrm{L}^{-1}$ for LLE.

A tentative study to estimate the contribution of a specific compound to the aroma of a whiskey, on the basis of their odour activity values (OAV) was made. Ethyl octanoate followed by isoamyl acetate and isobutyl alcohol, were found the most potent odour-active compounds.
\end{abstract} (C) 2007 Elsevier B.V. All rights reserved.

Keywords: Whiskey; Volatile organic compounds; Liquid-liquid extraction; Solid-phase microextraction; Odour activity values

\section{Introduction}

Analysis of flavour/aroma compounds is one of the most important steps in the evaluation of whiskey quality. Being a combination of taste and olfaction senses, these characteristics are crucial factors in consumer acceptance of drinks and foods.

It has been reported [1-3] that whiskeys have several volatile compounds, which belong to a great variety of families such as: ethyl esters, higher alcohols, fatty acids, higher alcohols acetates, carbonyl compounds such as aldehydes and ketones, sulphur compounds, furanic compounds, lactones, volatile phenols, among others. This great diversity of compounds are produced through metabolic pathways and their genesis depends on many factors related to raw materials and the subsequent pro-

\footnotetext{
* Corresponding author. Tel.: +351 291705112; fax: +351 291705149.

E-mail address: jsc@uma.pt (J.S. Câmara).
}

cesses of mashing, fermentation, distillation and ageing, others are oak derived, while others depend on the type of technological treatment. Many of these compounds are common to different whiskeys but differ analytically in terms of the relative amount. The qualitative and quantitative study with some whiskeys available commercially, is an important database for ensuring process continuity and product authenticity $[4,5]$.

Ethyl esters are an essential family among the aroma components of whiskeys. Even present in small amounts, they have very intense odour characterized by pleasant aromas, such as fruity and floral aromas that generally contribute positively to the global quality of whiskeys [5]. The higher alcohols are also an important family, quantitatively and qualitatively speaking, being characterized by their strong and pungent smell and taste, causing a positive contribution to the overall sensory properties when present at levels lower than $300 \mathrm{mg} \mathrm{L}^{-1}$. Higher alcohol acetates are correlated with freshness and fruitness character, while fatty acids can contribute with fruity, cheese, fatty and 
rancid notes to the whiskeys sensory. However, not all compounds contribute to the same extent to whiskey aroma. The particular importance of each compound to the final aroma is related to its odour perception threshold, which is defined as the lowest concentration that can be detected by smelling. In fact, if the concentration/olfactory threshold ratio of each compound, known as the odour activity value (OAV) is $\geq 1$, this allows to estimate the contribution of a specific compound to aroma of a whiskey. To our knowledge no scientific studies on the most potent aroma compounds of commercial whiskey samples, has been previously published.

In order to achieve a practical and reliable method for the analysis of volatiles in complex matrices such as whiskey samples, several extraction methods have been developed and used, including steam distillation, liquid-liquid microextraction [6-8], simultaneous distillation-solvent extraction [9], solid-phase extraction [6], supercritical fluid extraction [10], microwaves extraction [11] and ultrasound extraction [12], among others. Although offering specific advantages under certain circumstances, these analytical methods have some drawbacks such as the possibility of contamination with solvents, and later solvent concentration, generation of artifacts and the length of time analysis. In spite of these inconvenient, LLE methods continue to be the reference technique for determination of volatile constituents from several beverages. An advantage of this method is that all volatile compounds (low, medium and high volatility) can be analysed in one extraction step, but the method may require solvent evaporation, which, in some cases, results in the loss or degradation of some compounds.

Pawliszyn and co-workers in 1990 [13-15] develop a new variation of adsorption techniques called solid-phase microextraction (SPME). Compared to conventional techniques this new technique offers many advantages such as high sensitivity and reproducibility, does not require solvent and combines extraction and pre-concentration in a single step without pre-treatment of samples. Moreover, it is fast, inexpensive and requires small sample volumes. This technique, based on absorption and/or adsorption mechanism, depending on the fibre coating, can be successfully applied for polar and non-polar compounds in gaseous, liquid and solid samples and can be easily coupled with various analytical instruments such as GC, GC-MS, HPLC and LC-MS [16-23]. It has been used routinely in combination with gas chromatography (GC) and gas chromatography coupled to mass spectrometry with ion trap detection ( $\mathrm{GC}-\mathrm{ITD} M S)$, and successfully applied to a wide variety of compounds, especially for the extraction of volatile and semi-volatile organic compounds from environmental [24], biological [25] and food [26-31] samples. More recently Deng et al. [32] developed a SPME methodology for investigation of long cancer volatile biomarkers. The same authors applied HS-SPME with on-fibre derivatization for the determination of hexanal and heptanal in normal blood and lung cancer blood [33].

Lately 1990s, a new technique, namely stir bar sorptive extraction (SBSE) has also been developed by Baltussen et al. [34] and applied to the extraction of volatile constituents [35]. Zalacain et al. [36] used this technique to the analysis of wine primary aroma compounds, while Demyttenaere et al. [37] used the same methodology to extract whiskey volatiles. The characterization of the main chemical composition and the aroma profile of Madeira wine by sorptive extraction techniques were made by Alves et al. [38].

The present work was carried out to evaluate the performance of two extraction methods (LLE and dynamic HS-SPME) in the determination of volatile compounds from commercial Scotch whiskeys. Seven different extraction solvents $\left[\mathrm{CH}_{2} \mathrm{Cl}_{2}, \mathrm{H}\right.$ (n-hexane), $\mathrm{CH}_{2} \mathrm{Cl}_{2}-\mathrm{DE}$ (diethyl ether) (3:1 and 1:3), $\mathrm{CH}_{2} \mathrm{Cl}_{2}-\mathrm{H}$ (3:1 and 1:3) and DE-H (1:3)] and two kinds of commercially available fibres: carboxen/polydimethylsiloxane (CAR/PDMS, $75 \mu \mathrm{m}$ ), apolar, and carbowax/divinylbenzene (CW/DVB, $65 \mu \mathrm{m})$, polar, were used to test the extraction efficiency of volatile compounds. The best solvent and SPME fibre were applied by employing GC with flame ionisation detector (FID) to the determination of absolute content of whiskey volatiles and GC-MS to the volatile identification. The selectivity of each method for specific classes of flavour compounds was evaluated. Linearity, detection and quantification limits, and precision of the whole analytical procedure have also been calculated for the 25 target compounds selected to study the methods performance. Given the lack of information about the whiskeys odour-active compounds, the levels of recognized odorants were used to establish exactly the flavour differences between the whiskeys, and to calculate the odour activity values in order to elucidate the most potent aroma compounds of the studied samples. The results obtained applying the two analytical procedures are shown and discussed.

\section{Experimental}

\subsection{Chemicals and materials}

All reagents used were of analytical quality. $n$-Hexane (99\%) and diethyl ether (99.5\%) were supplied by Lab-Scan (Dublin, Ireland); ethanol absolute ( $\geq 99.5 \%)$, solid anhydrous sodium sulphate $(99 \%)$ and analytical-grade hydrochloric acid $(\approx 37 \%)$ used to adjust the standards $\mathrm{pH}$, were purchased from Panreac Quimica SA (Barcelone, Spain). Dichloromethane ( $\geq 99.8 \%)$, sodium hydroxide $(>99 \%)$, sodium chloride $(99.5 \%)$ that was used to obtain the adequate ionic strength (decrease the solubility of the aroma molecules which then partition more readily into the headspace improving the adsorption of analytes in SPME analysis), were supplied by Merck (Darmstadt, Germany). Methanol of Chromasolv quality $(\geq 99.9 \%)$ and the standards of aroma compounds, which ranged from $98 \%$ to $99.5 \%$ purity, were obtained from Sigma-Aldrich (Steinheim, Germany). The $n$ alkane mixture, consisting of $\mathrm{C}_{8}$ to $\mathrm{C}_{20}$ straight-chain alkanes, was purchased from Fluka. Solvents did not require additional distillation, were used as received. Water was purified through a Milli-Q purification system (Millipore).

Seventy-five micrometers CAR/PDMS and $65 \mu \mathrm{m}$ of CW/DVB SPME fibres, purchased from Supelco (Bellefonte, PA, USA) were conditioned under helium at a flow-rate of $1.0 \mathrm{~mL} \mathrm{~min}^{-1}$ in the hot injection port of a gas chromatograph at $300{ }^{\circ} \mathrm{C}$ for $2 \mathrm{~h}$ for $\mathrm{CAR} / \mathrm{PDMS}$ and $220^{\circ} \mathrm{C}$ for $0.5 \mathrm{~h}$ for 
CW/DVB. Fiber blanks, taken prior to analysis, confirm the quality of conditioning.

Stock solution of target compounds to be determined was prepared in methanol. A mixed standard solution for the preparation of spiked samples was obtained diluting the stocks. All the standards solution was stored at $4{ }^{\circ} \mathrm{C}$ in the darkness, until use.

Synthetic whiskey samples were prepared by an ethanol solution at $12 \%(\mathrm{v} / \mathrm{v})$ to which hydrochloride acid $1 \mathrm{M}$ was added to adjust solution $\mathrm{pH}$.

\subsection{Whiskey samples}

A total of 24 commercial Scotch whiskey samples $(40 \%$ (v/v), alcohol), Famous Grouse (FG), Dewar's (DW), Red Label (RL), Black Label (BL), Grant's (GRA), Long Jonh (LJ), Ballantines (BAL) and Highland Clan (HC), three samples from each whiskey, were purchased from a local store (Funchal, Madeira Island) and frozen at $-28{ }^{\circ} \mathrm{C}$ until their analysis. Before extraction of the volatile compounds, the samples were unfrozen at $3-4{ }^{\circ} \mathrm{C}$. Commercial BL whiskey sample was used to select the best solvent and the fiber with higher extraction efficiency for whiskey volatile constituents.

The high ethanol concentration of the whiskeys required dilution to $12 \%(\mathrm{v} / \mathrm{v})$ alcohol for both LLE and SPME methods. This dilution minimized emulsion formation during LLE method and loss of sensitivity for most volatiles determined by SPME.

\subsection{Extraction methodologies}

\subsubsection{LLE method}

Quantitative analysis and identification of volatile compounds were carried out by the procedure described by Perestrelo et al. [39]. In accordance with this method, $50 \mathrm{~mL}$ of whiskey sample, to which $250 \mu \mathrm{L}$ of octan-3-ol and $1 \mathrm{~mL}$ of $4-$ methylpentan-2-ol, in hydro alcoholic solution $(1: 1, \mathrm{v} / \mathrm{v})$ at $422 \mathrm{mg} \mathrm{L}^{-1}$ as internal standards were added, was poured into a $100 \mathrm{~mL}$ flask. Five grams of sodium sulphate was added. The samples were then extracted twice with $5 \mathrm{~mL}$ of $\mathrm{CH}_{2} \mathrm{Cl}_{2}$. The solution was stirred during $15 \mathrm{~min}$ at $400 \mathrm{rpm}$. Both organic phases obtained were blended and dried over anhydrous sodium sulphate and concentrated to $500 \mu \mathrm{L}$ under a gentle stream of pure nitrogen (N45, Air Liquide, Portugal). Injection of the concentrated extract was made in split mode (split ratio, 1:10; sample size, $1 \mu \mathrm{L}$ ) in the GC-FID, for quantification and onto GC-MS for volatile identification.

\subsubsection{Solid-phase microextraction procedure}

After adjust to $12 \%$ (v/v) alcohol by dilution with distilled water, whiskey samples were adjusted to $\mathrm{pH} 3.3$ and the ionic strength was increased, using $\mathrm{NaCl}(30 \%)$, to improve the extraction efficiency. A $60 \mathrm{~mL}$ vial containing $35 \mathrm{~mL}$ of sample, spiked with octan-3-ol (Sigma-Aldrich) and 4-methylpentan-2ol, which were used as internal standards $(50 \mu \mathrm{L}$ of alcoholic solution at $422 \mathrm{mg} \mathrm{L}^{-1}$ ), was placed in a thermostatic block on a stirrer. The fibre was then exposed to the gaseous phase during $60 \mathrm{~min}$ at temperature of $40 \pm 1^{\circ} \mathrm{C}$. As stirring usually improves the extraction, because the static layer resistant to mass transfer is destroyed (facilitate mass transport between the bulk of the aqueous sample and the fibre), all the experiments were performed under constant stirring velocity $(1250 \mathrm{rpm})$. After extraction, the SPME fibre was withdrawn into the needle, removed from the vial and inserted into the hot injector port $\left(260^{\circ} \mathrm{C}\right)$ of the GC-MS system for $6 \mathrm{~min}$ where the extracted chemicals were desorbed thermally and transferred directly to the analytical column.

\subsection{Instrumental analysis}

\subsubsection{Gas chromatography $(G C)$ analysis}

A Hewlett-Packard HP 5890 series II gas chromatograph equipped with a split/splitless capillary injection port and flame ionization detector (FID) was used. Separation was performed on a fused silica capillary column DB-Waxetr: $30 \mathrm{~m} \times 0.25 \mathrm{~mm}$ I.D. $\times 0.5 \mu \mathrm{m}$ film thickness from JW Scientific (USA). The column was maintained at $40^{\circ} \mathrm{C}$ for 1 min after desorption and then ramped at $1^{\circ} \mathrm{C} \mathrm{min}{ }^{-1}$ to $120^{\circ} \mathrm{C}$ ( 2 min) followed by $1.7^{\circ} \mathrm{C} \mathrm{min}{ }^{-1}$ to $180^{\circ} \mathrm{C}$ where it was held for $1 \mathrm{~min}$ and finally to $220^{\circ} \mathrm{C}$ at $25^{\circ} \mathrm{C} \mathrm{min}^{-1}$ and held isothermally for $10 \mathrm{~min}$. The FID temperature was $300^{\circ} \mathrm{C}$ and the injector temperature $260^{\circ} \mathrm{C}$. The carrier gas was helium $(99.99995 \%)$ at a flowrate of $1 \mathrm{~mL} \mathrm{~min}^{-1}$. Hydrogen and air at 30 and $300 \mathrm{~mL} \mathrm{~min}^{-1}$, respectively, were used in FID, with nitrogen $\left(35 \mathrm{~mL} \mathrm{~min}^{-1}\right)$ as a make-up gas. A Star Chromatography workstation version 4.0 was used for acquiring and processing the data. Measured retention times and peak areas represented an average from three injections.

The quantification was based on the calibration curves of respective standards in the synthetic whiskeys, with octan-3ol and 4-methylpentan-2-ol as internal standards. Since the repeatability of the chromatographic method was very good (with coefficients of variation ranging from $2.0 \%$ to $12 \%$ in average), only tree injection of each $\mathrm{CH}_{2} \mathrm{Cl}_{2}$ extract was carried out. n-Alkane standards (Fluka) were run under the same chromatographic conditions as the samples, to calculate the Kovàts retention indices of the compounds.

\subsubsection{Gas chromatography-ion trap mass spectrometry $(G C-I T D M S)$ analysis}

The identification and confirmation of analytes identity in real samples was performed by a GC-ITDMS, Varian Star 3400 Cx Series II gas chromatograph equipped with Varian Saturn III mass selective detector and a Saturn GC-MS workstation software, in the electron impact mode (EI). Chromatographic conditions were similar to the described in the GC-FID analysis. The ion trap detector was set as follows: transfer line temperature $220^{\circ} \mathrm{C}$; manifold and trap temperatures $180^{\circ} \mathrm{C}$. The mass range was $m / z=30-300 \mathrm{amu}$, the emission current $15 \mu \mathrm{A}$ and the electron multiplier was set in the relative mode to the auto tune procedures. All mass spectra were acquired in the electron impact (EI) mode $\left(E_{i}=70 \mathrm{eV}\right.$, source temperature, $\left.180^{\circ} \mathrm{C}\right)$.

The identification of the volatile compounds was achieved by comparing their mass spectra with those stored in the US Government National Institute of Standards and Technology 
Table

Performance characterisitcs of liquid-liquid extraction method $\left(\mathrm{LLE}_{\left.\mathrm{CH}_{2} \mathrm{Cl}_{2}\right)}\right)$ concentration range, linearity, detection (LOD) and quantification (LOQ) limits, recoveries and yield extraction data

\begin{tabular}{|c|c|c|c|c|c|c|c|c|c|c|}
\hline Compound & Range concentration $\left(\mathrm{mg} \mathrm{L}^{-1}\right)$ & $r$ & Slope & Intercept & $\operatorname{LOD}\left(\mu \mathrm{g} \mathrm{L}^{-1}\right)$ & $\operatorname{LOQ}\left(\mu \mathrm{g} \mathrm{L}^{-1}\right)$ & Recovery (\%) & Yield (\%) & R.S.D. (\%) & IS \\
\hline \multicolumn{11}{|l|}{ Higher alcohols } \\
\hline Propan-1-ol & $0.40-28.91$ & 1.0000 & 0.21 & 0.22 & 1.65 & 5.50 & 84.67 & 106.94 & 5.57 & $3-\mathrm{OCT}$ \\
\hline 2-Methylpropan-1-ol & $0.26-20.12$ & 0.9989 & 1.41 & -0.01 & 0.50 & 1.66 & 69.05 & 84.00 & 3.19 & $4 \mathrm{M} 2 \mathrm{P}$ \\
\hline Butan-1-ol & $0.74-29.16$ & 0.9995 & 0.24 & 0.04 & 1.21 & 4.04 & 85.76 & 123.04 & 7.06 & 3-OCT \\
\hline 3-Methylbutan-1-ol & $0.74-29.12$ & 0.9989 & 0.22 & 0.05 & 0.95 & 3.15 & 85.16 & 102.43 & 6.98 & $4 \mathrm{M} 2 \mathrm{P}$ \\
\hline Hexan-1-ol & $3.80-29.48$ & 0.9995 & 0.13 & 0.04 & 0.97 & 3.23 & 101.24 & 101.94 & 7.82 & $4 \mathrm{M} 2 \mathrm{P}$ \\
\hline Methionol & $0.54-42.12$ & 0.9995 & 0.05 & 0.03 & 1.39 & 4.62 & 100.77 & 109.18 & 7.81 & $4 \mathrm{M} 2 \mathrm{P}$ \\
\hline$\beta$-Phenylethanol & $0.47-36.83$ & 0.9985 & 0.14 & 0.14 & 2.79 & 9.29 & 101.18 & 83.27 & 9.36 & 3-OCT \\
\hline Benzyl alcohol & $0.48-37.62$ & 0.9989 & 0.12 & 0.09 & 2.38 & 7.95 & 105.46 & 102.87 & 8.48 & $4 \mathrm{M} 2 \mathrm{P}$ \\
\hline 2-Phenoxyethanol & $0.51-39.67$ & 0.9929 & 0.12 & 0.14 & 4.90 & 16.34 & 11428 & 113.30 & 7.81 & $4 \mathrm{M} 2 \mathrm{P}$ \\
\hline \multicolumn{11}{|l|}{ Acetate } \\
\hline Isoamyl acetate & $4.00-31.54$ & 1.0000 & 0.11 & 0.03 & 0.92 & 3.08 & 101.12 & 107.49 & 8.93 & $4 \mathrm{M} 2 \mathrm{P}$ \\
\hline \multicolumn{11}{|l|}{ Ethyl esters } \\
\hline Ethyl butanoate & $0.37-31.61$ & 1.0000 & 0.10 & 0.09 & 0.76 & 2.54 & 104.39 & 106.31 & 14.88 & $4 \mathrm{M} 2 \mathrm{P}$ \\
\hline Ethyl hexanoate & $0.80-31.43$ & 0.9995 & 0.13 & 0.08 & 1.22 & 4.06 & 100.97 & 103.52 & 10.05 & $4 \mathrm{M} 2 \mathrm{P}$ \\
\hline Ethyl lactate & $0.96-37.51$ & 0.9995 & 0.04 & 0.01 & 1.41 & 4.72 & 96.60 & 125.26 & 6.92 & $4 \mathrm{M} 2 \mathrm{P}$ \\
\hline Ethyl octanoate & $0.80-31.61$ & 0.9995 & 0.15 & 0.07 & 1.42 & 4.74 & 98.90 & 106.01 & 9.73 & $4 \mathrm{M} 2 \mathrm{P}$ \\
\hline Ethyl decanoate & $0.80-31.03$ & 1.0000 & 0.21 & -0.04 & 0.70 & 2.33 & 100.45 & 92.34 & 9.16 & $4 \mathrm{M} 2 \mathrm{P}$ \\
\hline Diethyl succinate & $0.48-37.69$ & 0.9995 & 0.11 & 0.01 & 4.43 & 14.77 & 106.18 & 95.89 & 9.16 & $4 \mathrm{M} 2 \mathrm{P}$ \\
\hline Ethyl dodecanoate & $5.60-124.84$ & 0.9959 & 0.44 & 0.46 & 12.48 & 41.59 & 92.49 & 115.18 & 11.37 & 3-OCT \\
\hline \multicolumn{11}{|l|}{ Fatty acids } \\
\hline Hexanoic acid & $0.43-33.72$ & 0.9969 & 0.08 & -0.13 & 3.18 & 10.60 & 88.93 & 89.57 & 16.25 & $4 \mathrm{M} 2 \mathrm{P}$ \\
\hline Octanoic acid & $0.42-32.79$ & 0.9959 & 0.08 & -0.13 & 3.73 & 12.44 & 93.62 & 88.71 & 19.42 & $4 \mathrm{M} 2 \mathrm{P}$ \\
\hline Decanoic acid & $0.72-55.99$ & 0.9965 & 0.13 & -0.07 & 8.90 & 29.68 & 82.69 & 96.42 & 13.11 & 3-OCT \\
\hline \multicolumn{11}{|l|}{ Carbonyl compounds } \\
\hline Acetaldehyde & $3.60-28.37$ & 0.9995 & 0.35 & 0.24 & 3.92 & 13.07 & 71.03 & 83.68 & 4.64 & 3-OCT \\
\hline Syringaldehyde & $3.50-54.86$ & 0.9939 & 0.05 & -0.01 & 7.65 & 25.49 & 90.13 & 99.77 & 13.67 & $4 \mathrm{M} 2 \mathrm{P}$ \\
\hline \multicolumn{11}{|l|}{ Furanic compounds } \\
\hline Furfural & $0.96-37.77$ & 0.9995 & 0.08 & -0.01 & 1.29 & 4.31 & 91.70 & 99.42 & 4.42 & $4 \mathrm{M} 2 \mathrm{P}$ \\
\hline 5-Methyl-2-furfural & $1.20-39.85$ & 0.9995 & 0.09 & 0.05 & 1.86 & 6.21 & 95.61 & 101.66 & 8.10 & $4 \mathrm{M} 2 \mathrm{P}$ \\
\hline \multicolumn{11}{|l|}{ Volatile phenol } \\
\hline Guaiacol & $0.46-36.18$ & 0.9985 & 0.13 & 0.12 & 2.40 & 8.01 & 102.74 & 123.13 & 8.62 & $4 \mathrm{M} 2 \mathrm{P}$ \\
\hline
\end{tabular}




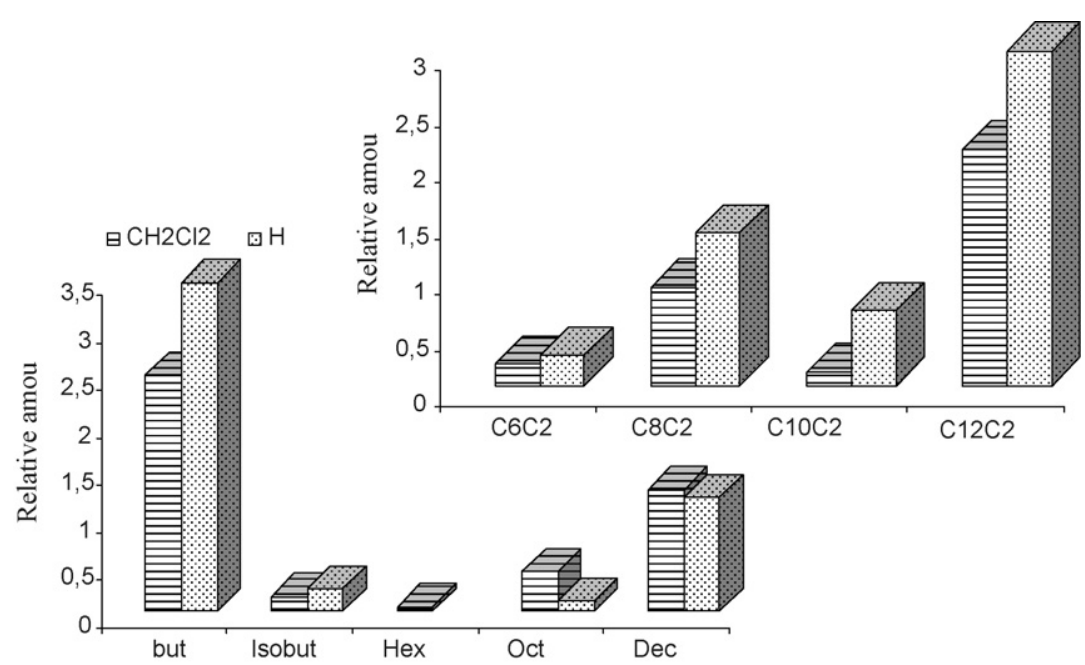

Fig. 1. Comparison of the extraction efficiency for different chemical families by LLE method using $\mathrm{CH}_{2} \mathrm{Cl}_{2}$ and $\mathrm{H}$ (But: butanoic acid; Isobut: 3-methylbutanoic acid; Hex: hexanoic acid; Oct: octanoic acid; Dec: decanoic acid; C6C2: ethyl hexanoate; C8C2: ethyl octanoate; C10C2: Ethyl decanoate; C12C2: ethyl dodecanoate).

(NIST) library and by the Kovàts retention indices calculated for each peak with reference to the normal alkanes $\mathrm{C}_{8}-\mathrm{C}_{20}$ series according to the following equation [40]:

$\mathrm{RI}=100 z+100\left[\frac{\mathrm{RT}_{i}-\mathrm{RT}_{z}}{\mathrm{RT}_{z+1}-\mathrm{RT}_{z}}\right]$

where $\mathrm{RI}$ is the retention index of the unknown peak, $\mathrm{RT}_{i}$ the retention time for the unknown peak, $\mathrm{RT}_{z}$ and $\mathrm{RT}_{z+1}$ are the retention times for the $n$-alkanes that bracket the unknown peak, $z$ is the number of carbon atoms in the $n$-alkane standard that elute just before the unknown peak. All experiments were carried out in triplicate.

\subsection{Analytical methods validation}

Twenty-five volatile target compounds (Table 1) were selected to study the methods performance. Calibrations have to be carried out for each compound and by the two methods
(LLE $\mathrm{CH}_{2} \mathrm{Cl}_{2}$ and $\mathrm{HS}-\mathrm{SPME}$ PDMS) in order to achieve accurate quantitative results.

For linearity study, calibration graphs were established with five standard solutions in synthetic whiskey. Duplicate calibration graphs, were drawn by the least-squares linear regression method using the relative peak area as response versus concentration. Regression slope and origin intercept were calculated by linear least-squares regression. Repeatability (precision) was evaluated by the relative standard deviation of six independent assays performed under the same analytical conditions in the shortest period of time. For each assay the mean values, standard deviation and coefficients of variation for all compounds were calculated.

The recovery rates of volatile compounds were evaluated by addition of known amounts of the target compounds to the BL whiskey sample. Samples were submitted to six successive extractions with $\mathrm{CH}_{2} \mathrm{Cl}_{2}$ and with a CAR/PDMS fibre. For each volatile compound the recovery rate was calculated by the ratio

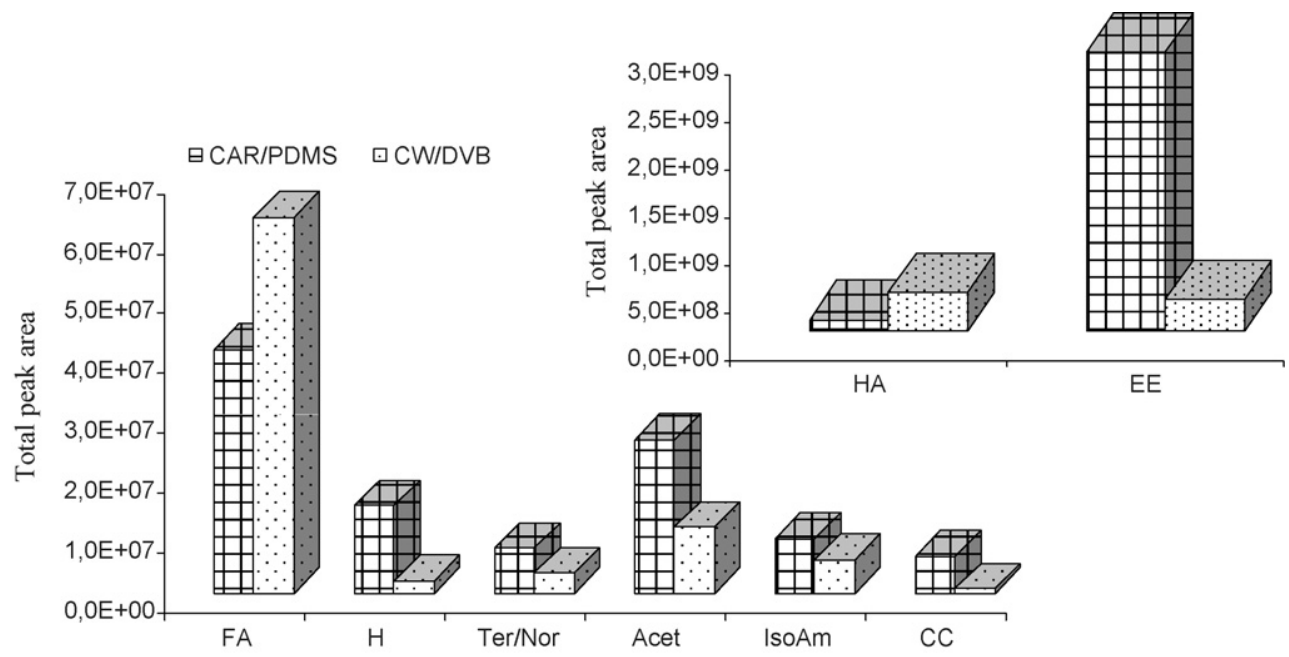

Fig. 2. Influence of the type of HS-SPME fibre coatings on the GC-MS peak area for the total fraction of the volatile compounds in BL whiskey sample (extraction temperature: $40^{\circ} \mathrm{C}$; extraction time: $60 \mathrm{~min}$ ) (HA: higher alcohols; EE: ethyl esters; FA: fatty acids; $\mathrm{H}$ : hydrocarbons; Ter/Nor: monoterpenes and $\mathrm{C}_{13}$-norisoprenoids; Acet: higher alcohol acetates; Isoam: isoamyl esters; CC: carbonyl compounds). 
$\left(\left(C_{1}-C_{0}\right) / C_{2}\right) \times 100$, where $C_{0}$ is the concentration of the analyte in the whiskey before addition, $C_{1}$ the concentration of the analyte in spiked whiskey sample and $C_{2}$ is the amount of the analyte added to whiskey sample.

The limits of detection (LOD) were estimated as the concentration of the analyte that produce a signal-to-noise ratio of three times the standard deviation of the $y$-residuals of the calibration graph, which is $3 s_{y / x} / b$, where $s_{y / x}$ is the blank standard deviation and $b$ is the slope of the line regression. The linear range experiments provide the necessary information to calculate the limits of detection, by extrapolating from the lowest concentration point on the linear calibration curve. The limit of quantification (LOQ) can also be estimated as the concentration of analyte producing a signal 10 times that of the noise.

Extraction yield were calculated using the internal standard method. Standard solutions containing the volatiles and the internal standard at known concentrations were injected into the chromatograph system. The response factor $(K)$ of each compound was calculated using the following equation: $K=A_{\mathrm{c}} \times C_{\mathrm{IS}} / A_{\mathrm{IS}} \times C_{\mathrm{c}}$, where $A_{\mathrm{c}}$ is the area of the compound, $A_{\text {IS }}$ area of the internal standard, $C_{\mathrm{c}}$ concentration of the compound and $C_{\mathrm{IS}}$ is the concentration of the internal standard. Then $50 \mathrm{~mL}$ of synthetic whiskey containing the volatile compounds at known concentrations was subjected to the LLE procedure described above. The concentration of each compound can be calculated applying the response factor equation $(K)$. Taking into account the organic phase volume, the amount of the extracted analyte was calculated and the yield expressed as: $\%=C_{\mathrm{e}} / C_{0} \times 100$, where $C_{\mathrm{e}}$ is the concentration of the extracted analyte and $C_{0}$ is the initial concentration. A similar procedure, to the described in Section 2.3.2, was made for HS-SPME ${ }_{\text {CAR/PDMS. }}$.

\subsection{Whiskey samples differentiation}

In this study, eight different commercial whiskeys were analyzed in triplicate following the methodology proposed. Whiskey sample differentiation was performed with SPSS program Version 13.0 statistical package for Windows (SPSS, Chicago, IL).

\section{Results and discussion}

First, the commercial whiskeys were analysed by GC-MS to identify the volatile fraction constituents. Many compounds were identified, but only 25 (Table 1) including higher alcohols, ethyl esters, fatty acids and furanic compounds, were selected to study the figures of merit of the methods.

Table 2

Performance parameters of the solid-phase microextraction method (HS-SPME $\mathrm{CAR}_{\text {PDMS }}$ ): concentration range, linearity, detection (LOD) and quantification (LOQ) limits

\begin{tabular}{|c|c|c|c|c|c|c|c|c|}
\hline Compounds & Range concentration $\left(\mathrm{mg} \mathrm{L}^{-1}\right)$ & $r$ & Slope & Intercept & $\operatorname{LOD}\left(\mu \mathrm{g} \mathrm{L}^{-1}\right)$ & $\operatorname{LOQ}\left(\mu \mathrm{gL}^{-1}\right)$ & R.S.D. (\%) & IS \\
\hline \multicolumn{9}{|l|}{ Higher alcohols } \\
\hline 2-Methylbutan-1-ol & $3.90-60.0$ & 0.9985 & 18.37 & -6.48 & 5.44 & 18.12 & 7.40 & $4 \mathrm{M} 2 \mathrm{P}$ \\
\hline Butan-1-ol & 20.0-200.0 & 0.9955 & 15.10 & 2.80 & 10.26 & 34.20 & 5.17 & $4 \mathrm{M} 2 \mathrm{P}$ \\
\hline 3-Methylbutan-1-ol & $12.75-176.05$ & 0.9969 & 0.96 & -4.68 & 19.03 & 63.43 & 4.25 & $4 \mathrm{M} 2 \mathrm{P}$ \\
\hline Hexan-1-ol & $10.14-219.77$ & 0.9969 & 0.94 & -2.81 & 8.03 & 26.77 & 12.78 & 3-OCT \\
\hline Methionol & $0.46-11.26$ & 0.9989 & 12.96 & -1.94 & 0.67 & 2.22 & 9.64 & 3-OCT \\
\hline$\beta$-Phenylethanol & $7.70-228.33$ & 0.9995 & 2.72 & -1.00 & 8.55 & 9.43 & 6.31 & 3-OCT \\
\hline Benzyl alcohol & $0.93-87.64$ & 0.9989 & 0.82 & 0.25 & 1.59 & 5.32 & 11.22 & $4 \mathrm{M} 2 \mathrm{P}$ \\
\hline 2-Phenoxyethanol & $17.95-151.78$ & 0.9935 & 0.15 & 6.05 & 13.43 & 44.76 & 9.16 & 3-OCT \\
\hline \multicolumn{9}{|l|}{ Acetate } \\
\hline Isoamyl acetate & $0.39-24.78$ & 0.9989 & 2.10 & 0.84 & 1.44 & 4.81 & 4.97 & $4 \mathrm{M} 2 \mathrm{P}$ \\
\hline \multicolumn{9}{|l|}{ Ethyl esters } \\
\hline Ethyl butanoate & $0.91-122.03$ & 0.9989 & 55.73 & 4.39 & 2.37 & 7.91 & 13.75 & 3-OCT \\
\hline Ethyl hexanoate & $0.91-24.92$ & 0.9995 & 67.71 & 6.23 & 1.06 & 3.53 & 3.97 & $4 \mathrm{M} 2 \mathrm{P}$ \\
\hline Ethyl lactate & $4.10-29.53$ & 0.9969 & 0.02 & 0.01 & 3.06 & 10.19 & 7.83 & $4 \mathrm{M} 2 \mathrm{P}$ \\
\hline Ethyl octanoate & $0.40-4.90$ & 1.0000 & 459.48 & -15.55 & 0.13 & 0.42 & 4.98 & 3-OCT \\
\hline Ethyl decanoate & $0.40-4.81$ & 0.9995 & 117.40 & -4.14 & 0.24 & 0.79 & 10.54 & 3-OCT \\
\hline Diethyl succinate & $1.49-10.52$ & 0.9955 & 0.74 & 0.42 & 1.34 & 4.48 & 6.81 & $4 \mathrm{M} 2 \mathrm{P}$ \\
\hline Ethyl dodecanoate & $0.40-4.37$ & 0.9995 & 75.19 & -29.15 & 0.20 & 0.66 & 13.05 & 3-OCT \\
\hline \multicolumn{9}{|l|}{ Fatty acids } \\
\hline Hexanoic acid & $1.60-92.77$ & 0.9995 & 0.408 & 0.10 & 3.02 & 10.08 & 8.89 & $4 \mathrm{M} 2 \mathrm{P}$ \\
\hline Octanoic acid & $3.20-90.87$ & 1.0000 & 1.081 & 0.91 & 2.50 & 8.32 & 14.78 & $4 \mathrm{M} 2 \mathrm{P}$ \\
\hline Decanoic acid & $7.90-58.77$ & 0.9959 & 1.921 & 2.46 & 6.91 & 23.03 & 2.71 & $4 \mathrm{M} 2 \mathrm{P}$ \\
\hline \multicolumn{9}{|l|}{ Furanic compounds } \\
\hline Furfural & $2.9-14.26$ & 0.9985 & 9.00 & -1.24 & 1.07 & 3.56 & 10.11 & 3-OCT \\
\hline 5-Methyl-2-furfural & $2.5-11.77$ & 0.9975 & 12.53 & -2.39 & 1.09 & 3.64 & 12.04 & 3-OCT \\
\hline \multicolumn{9}{|l|}{ Volatile phenol } \\
\hline Guaiacol & $0.90-10.79$ & 0.9995 & 7.22 & 0.54 & 0.54 & 1.79 & 7.52 & 3-OCT \\
\hline
\end{tabular}


Table 3

Comparison of liquid-liquid extraction using dichloromethane as extraction solvent $\left(\mathrm{LLE}_{\mathrm{CH}_{2} \mathrm{Cl}_{2}}\right)$ and solid-phase microextraction using two different coatings (HS-SPME ${ }_{\mathrm{CAR} / \mathrm{PDMS}}$ and HS-SPME $\mathrm{CW}_{\mathrm{CDVB}}$ ) analysis of chemical composition of the main volatile compounds in BL whiskey

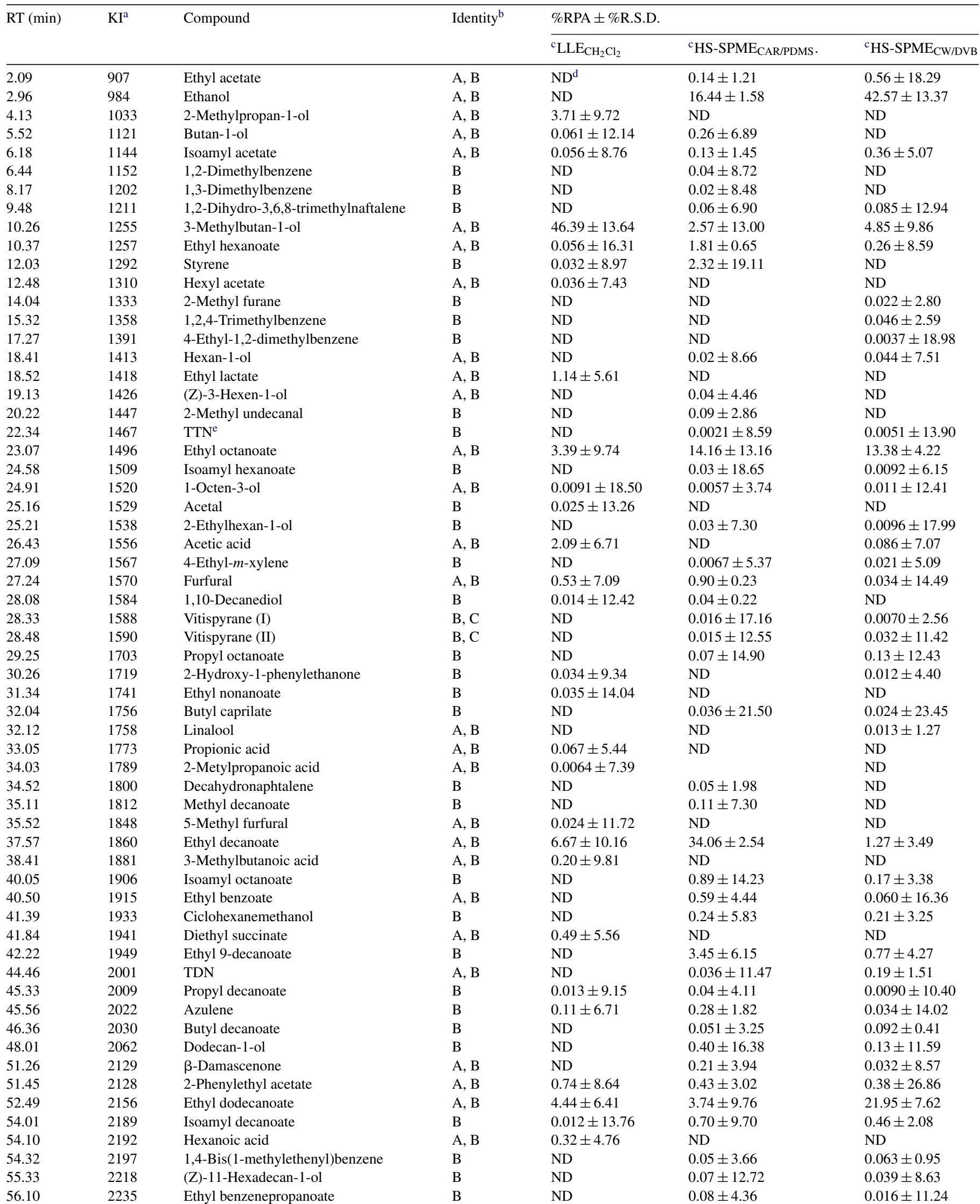


Table 3 (Continued)

\begin{tabular}{|c|c|c|c|c|c|c|}
\hline \multirow[t]{2}{*}{ RT (min) } & \multirow[t]{2}{*}{$\mathrm{KI}^{\mathrm{a}}$} & \multirow[t]{2}{*}{ Compound } & \multirow[t]{2}{*}{ Identity $^{\mathrm{b}}$} & \multicolumn{3}{|c|}{$\%$ RPA $\pm \%$ R.S.D. } \\
\hline & & & & ${ }^{\mathrm{c}} \mathrm{LLE}_{\mathrm{CH}_{2} \mathrm{Cl}_{2}}$ & ${ }^{\mathrm{c}} \mathrm{HS}-\mathrm{SPME} \mathrm{CAR}_{\mathrm{C} / \mathrm{PDMS}}$ & ${ }^{\mathrm{c}} \mathrm{HS}-\mathrm{SPME} \mathrm{CW}_{\mathrm{CWVB}}$ \\
\hline 57.31 & 2257 & Benzeneacetaldehyde & B & $0.31 \pm 10.14$ & ND & ND \\
\hline 57.81 & 2272 & $\alpha$-Ionol & A, B & ND & $0.35 \pm 8.70$ & $0.087 \pm 2.74$ \\
\hline 58.50 & 2287 & 2-Phenylethanol & A, B & $5.52 \pm 12.40$ & $1.00 \pm 5.99$ & $0.24 \pm 17.52$ \\
\hline 61.11 & 2301 & Whiskey lactone & $\mathrm{B}$ & $0.17 \pm 7.34$ & ND & ND \\
\hline 61.23 & 2314 & 1,8-Dimetyl naphthalene & $\mathrm{B}$ & ND & ND & $0.0067 \pm 6.78$ \\
\hline 61.35 & 2346 & 1,14-Tetradecanediol & B & ND & $0.31 \pm 6.88$ & $0.19 \pm 4.55$ \\
\hline 62.31 & 2365 & Bifenyl & $\mathrm{B}$ & ND & $0.01 \pm 2.07$ & $0.012 \pm 3.41$ \\
\hline 65.19 & 2423 & 2-Methoxyphenol & A, B & $0.026 \pm 14.61$ & ND & ND \\
\hline 65.74 & 2431 & 2-Methyl phenol & A, B & $0.026 \pm 15.06$ & $0.023 \pm 1.93$ & $0.033 \pm 14.97$ \\
\hline 66.02 & 2440 & Ethyl tetradecanoate & A, B & $0.604 \pm 9.57$ & $0.41 \pm 0.54$ & $0.97 \pm 8.15$ \\
\hline 66.24 & 2447 & Ethyl laurate & A, B & ND & $0.0023 \pm 8.47$ & $0.039 \pm 14.97$ \\
\hline 66.69 & 2456 & Nerolidol & $\mathrm{A}, \mathrm{B}$ & $0.062 \pm 12.18$ & $0.17 \pm 0.29$ & $0.16 \pm 13.53$ \\
\hline 67.45 & 2468 & Octanoic acid & A, B & $4.01 \pm 8.15$ & $2.22 \pm 0.83$ & $1.37 \pm 19.76$ \\
\hline 68.18 & 2495 & Ethyl 3-hydroxyhexanoate & B & ND & $0.0067 \pm 16.11$ & $0.095 \pm 5.63$ \\
\hline 70.09 & 2512 & 4-Methyl phenol & B & $0.085 \pm 11.61$ & ND & ND \\
\hline 70.52 & 2523 & 2-Ethyl phenol & B & $0.014 \pm 16.23$ & ND & ND \\
\hline 74.04 & 2554 & Cyclododecanemethanol & B & $0.72 \pm 11.47$ & $0.054 \pm 13.61$ & $0.75 \pm 5.83$ \\
\hline 75.31 & 2591 & 4-Ethyl phenol & B & $0.045 \pm 10.34$ & ND & ND \\
\hline 77.32 & 2667 & Ethyl hexadecanoate & A, B & $1.06 \pm 7.76$ & $0.05 \pm 27.07$ & $0.34 \pm 21.16$ \\
\hline 78.10 & 2683 & Ethyl 9-hexadecenoate & B & $1.20 \pm 4.12$ & $0.03 \pm 8.48$ & $0.74 \pm 7.75$ \\
\hline 79.14 & 2704 & Decanoic acid & A, B & $9.01 \pm 11.07$ & $4.08 \pm 0.70$ & $4.53 \pm 10.94$ \\
\hline 82.29 & 2772 & Oleyl alcohol & $\mathrm{B}$ & $0.79 \pm 5.73$ & $0.03 \pm 1.03$ & $0.19 \pm 16.30$ \\
\hline 85.30 & 2828 & Benzoic acid & A, B & ND & $0.04 \pm 19.15$ & ND \\
\hline 86.20 & 2846 & Dodecanoic acid & A, B & $4.08 \pm 7.91$ & $0.93 \pm 2.12$ & $1.51 \pm 9.85$ \\
\hline 87.54 & 2865 & 5-Hydroxymethyl furfural & $\mathrm{A}, \mathrm{B}$ & $0.53 \pm 8.53$ & ND & ND \\
\hline 88.51 & 2894 & Vanillin & A, B & $0.46 \pm 12.41$ & ND & ND \\
\hline
\end{tabular}

${ }^{a}$ Experimentally determined Kovàts indices on the DB-Waxetr column, relative to $\mathrm{C}_{8}-\mathrm{C}_{20}$ hydrocarbons.

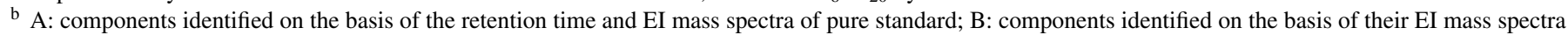
only; C: mass spectra agreed with literature data [42].

c Averages of three independent extractions.

d Not detected.

e 1,2,3,4-Tetrahydro-1,1,6-trimethylnapthalene.

\subsection{Solvent and fibre selection}

The choice of the extraction solvent depends on the type of food and the information needed. It is of great importance to recover an aromatic extract that as representative as possible of the product. Initially, some preliminary experiments were performed in order to establish the most suitable extraction solvent. Two solvents, $\mathrm{CH}_{2} \mathrm{Cl}_{2}, \mathrm{H}$, and five mixtures $\mathrm{CH}_{2} \mathrm{Cl}_{2}-\mathrm{DE}$ (3:1 and 1:3), $\mathrm{CH}_{2} \mathrm{Cl}_{2}-\mathrm{H}$ (3:1 and 1:3) and DE-H (1:3), and two SPME fibres (CAR/PDMS and CW/DVB) were investigated and evaluated. More than 50 compounds were detected and identified in concentration above $0.05 \%$ in the volatile fractions obtained by $\mathrm{CH}_{2} \mathrm{Cl}_{2}$. The total composition of volatile fractions isolated by $\mathrm{CH}_{2} \mathrm{Cl}_{2}-\mathrm{DE}$ (3:1 and 1:3), and $\mathrm{CH}_{2} \mathrm{Cl}_{2}$ differed significantly $(p<0.05)$ from $\mathrm{H}, \mathrm{CH}_{2} \mathrm{Cl}_{2}-\mathrm{H}(1: 3)$ and $\mathrm{DE}-\mathrm{H}$ (1:3). Highest extraction efficiency of whiskey volatile compounds was obtained when $\mathrm{CH}_{2} \mathrm{Cl}_{2}$ was used as solvent extraction. $\mathrm{H}$ extracted the lowest volatile fraction (about $24 \%$ of $\mathrm{CH}_{2} \mathrm{Cl}_{2}$ ). Similar amounts of volatiles were extracted when using either $\mathrm{CH}_{2} \mathrm{Cl}_{2}-\mathrm{DE}$ (3:1 and 1:3) (94 and $87 \%$ of $\mathrm{CH}_{2} \mathrm{Cl}_{2}$, respectively) or $\mathrm{CH}_{2} \mathrm{Cl}_{2}-\mathrm{H}$ (3:1) (82\% of $\left.\mathrm{CH}_{2} \mathrm{Cl}_{2}\right) . \mathrm{CH}_{2} \mathrm{Cl}_{2}$ is a very good extraction solvent, because all the target compounds were extracted and the yields were bigger in most cases, hence, it was the solvent chosen for extraction/isolation the target compounds from whiskeys by LLE. Fig. 1 compares the main fatty acids and ethyl esters found in $\mathrm{CH}_{2} \mathrm{Cl}_{2}$ extract of BL whiskey with those obtained by using $\mathrm{H}$ as extraction solvent.

The main volatile compounds found in $\mathrm{CH}_{2} \mathrm{Cl}_{2}$ extracts of BL whiskey were 3-methylbutan-1-ol with a relative peak area (RPA) of 46.4, decanoic acid (RPA $=9.0)$, ethyl decanoate $(\mathrm{RPA}=6.7), \beta$-phenylethanol $(\mathrm{RPA}=5.5)$, and in lower extent dodecanoic $(\mathrm{RPA}=4.1)$ and octanoic $(\mathrm{RPA}=4.0)$ acids. 3Methylbutan-1-ol (RPA =7.3), butanoic acid (RPA = 3.5), ethyl dodecanoate $(\mathrm{RPA}=2.9)$ and ethyl octanoate $(\mathrm{RPA}=1.4)$, were the main compounds found in $n$-hexane extract.

The relative amount of the higher alcohols, dropped considerably from $88.44 \%\left(\mathrm{CH}_{2} \mathrm{Cl}_{2}-\mathrm{DE}, 3: 1\right)$ to $44.14 \%(\mathrm{H})$, whilst the ethyl esters fraction rose from $3.92 \%\left(\mathrm{CH}_{2} \mathrm{Cl}_{2}\right)$ to $24.20 \%$ (H).

To investigate the extraction yields of the whiskey volatile components by HS-SPME, two fibre coatings, CAR/PDMS and CW/DVB, were used. Some experimental factors which influence the HS-SPME extraction yield, namely time required for the target analytes to reach equilibrium and extraction temperature, were previously evaluated by Câmara et al. [41]. The equilibration temperature was investigated by performing the analysis at four different temperatures $\left(25,40,50\right.$ and $\left.60^{\circ} \mathrm{C}\right)$ at 
fixed equilibration time of $60 \mathrm{~min}$. To select an optimal equilibration exposure time of the SPME fibre, extractions were performed at 5, 15, 30, 45 and $60 \mathrm{~min}$ [41]. In view of the obtained results, a temperature of $40^{\circ} \mathrm{C}$ and an extraction time of $60 \mathrm{~min}$ were chosen as the optimized conditions to carrying the analysis of all the whiskey samples under investigation. For reasons of comparability all tests were carried out with the same whiskey sample (BL). The peak areas of the total free fraction present in the BL whiskey were used for the evaluation of the optimal fibre. With the HS-SPME method, more than 60 volatile compounds were identified by using the CAR/PDMS and CW/DVB coatings. The results were shown in Fig. 2, indicating that the semi-polar CAR/PDMS fibre was more efficient than the CW/DVB fibre for extracting total volatiles in whiskeys. Therefore, this fibre was chosen for the remaining studies including validation. CAR/PDMS coating is less polar than CW/DVB, thus it is widely used for the extraction of non-polar compounds. For volatile low-molecular-mass and polar compounds like ketones and alcohols polar coatings like CW/DVB work better. From Fig. 2, it can be observed that the two fibres show different selectivity to different groups of compounds. The ethyl esters from fatty acids (EE) have a larger affinity for CAR/PDMS fibre. This coating has better sensitivity for hydrocarbons $(\mathrm{H})$, monoterpenes and $C_{13}$ norisoprenoids (Ter/Nor), higher alcohol acetates (Acet), isoamyl esters (IsoAm) and carbonyl compounds (CC). Higher alcohols (HA) and fatty acids (FA) were more effectively extracted by using the CW/DVB coating.

The results presented above suggest that there is a great variability in the aroma compounds obtained, depending on the solvent and the fibre coating employed. Some characteristic compounds of whiskey aroma were isolated by the both methods, such as 3-methylbutan-1-ol, $\beta$-phenylethanol, ethyl esters: hexanoate, octanoate, decanoate, dodecanoate, tetradecanoate and hexadecanoate, and fatty acids: octanoic, decanoic and dodecanoic.

\subsection{LLE and headspace SPME: performance characteristics}

Once the extraction solvent (for LLE method) and the fibre (for SPME method) were selected, the performance characteristics of the methods in terms of linearity, precision and accuracy, were evaluated. The results are shown in Table $1\left(\mathrm{LLE}_{\left.\mathrm{CH}_{2} \mathrm{Cl}_{2}\right)}\right)$ and Table 2 (SPME $\mathrm{CAR}_{\mathrm{CADMS}}$ ). Other analytical parameters that have been studied include the limits of detection (LOD) and quantification (LOQ), the percentage of recovery and the extraction yield.

The linearity of the method was evaluated through the construction of two calibration curves for each analyte (five levels of concentration were tested), using the same analytical conditions of the sample. For each compound the dynamic concentration ranges together with the response factor for each of the analytes are shown in Table 1 ( $\mathrm{LLE}_{\mathrm{CH}_{2} \mathrm{Cl}_{2}}$ ) and Table 2 ( $\mathrm{SPME}_{\mathrm{CAR} / \mathrm{PDMS}}$ ). In general, the volatile compounds have shown a good linearity in the range of concentrations studied, as regression coefficients $(r)$ vary between 0.9929 ( $\beta$-phenoxyethanol) and
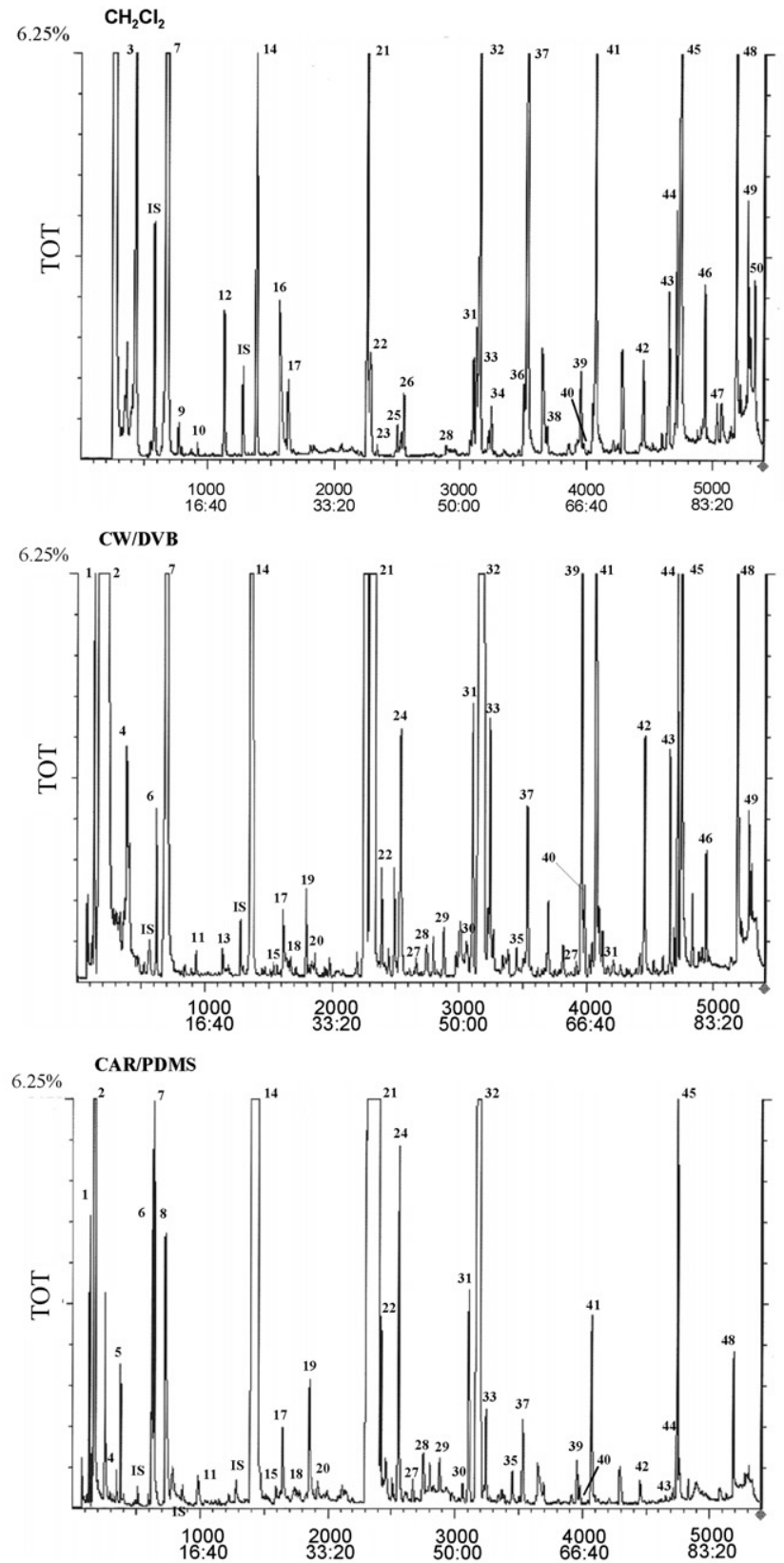

Fig. 3. Comparison of TIC chromatograms of the volatile fraction extracted/isolated from BL whiskey sample obtained by LLE method using $\mathrm{CH}_{2} \mathrm{Cl}_{2}$ as extraction solvent (LLE $\mathrm{CH}_{2} \mathrm{Cl}_{2}$ ) and by dynamic HS-SPME using

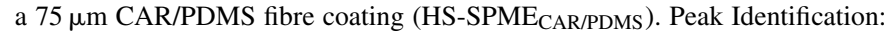
1: ethyl acetate; 2 : ethanol; 3: 2-methylpropan-1-ol; 4: butan-1-ol; 5: isoamyl acetate; IS: 4-methylpentan-2-ol; 6: ethyl hexanoate; 7: 3-methylbutan-1ol; 8: styrene; 9: acetal; 10: hexyl acetate; 11: ethyl heptanoate; IS: octan-3-ol; 12: ethyl latate; 13: hexan-1-ol; 14: ethyl octanoate; 15: linalool; 16: acetic acid; 17 : furfural; 18: vitispirane (isomer I + II); 19: propyl octanoate; 20: butyl caprylate; 21: ethyl decanoate; 22: isoamyl octanoate; 23: butanoic acid; 24: trans-ethyl 2-decenoate; 25: 3-methylbutanoic acid; 26: diethyl succinate; 27: azulene; 28 : buthyl decanoate; 29: dodecan-1-ol; 30: $\beta$-damascenone; 31: 2-phenylethanol acetate; 32: ethyl dodecanoate; 33: isoamyl decanoate; 34: hexanoic acid; $35: \alpha$ ionol; 36: benzeneacetaldehyde; 37: $\beta$-phenylethanol; 38: cis-whiskey lactone; 39: ethyl tetradecanoate; 40: nerolidol; 41: octanoic acid; 42: 1,12 dodecanediol; 43: ethyl hexadecanoate; 44: ethyl 9-hexadecanoate; 45: decanoic acid; 46: cyclododecanemethanol; 47: ethyl succinate; 48: dodecanoic acid; 49: 5 (hydroxymethyl) furfural; 50: vanillin. 


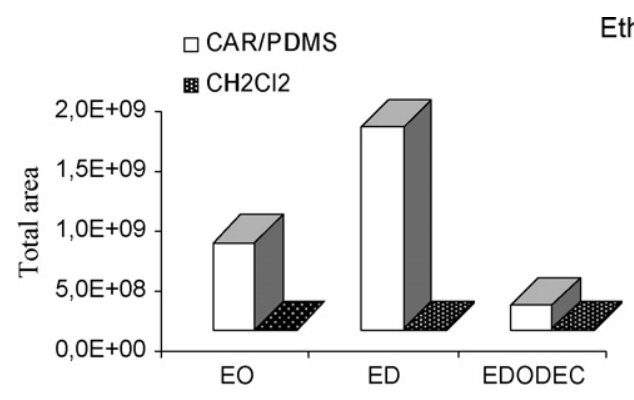

Ethyl esters
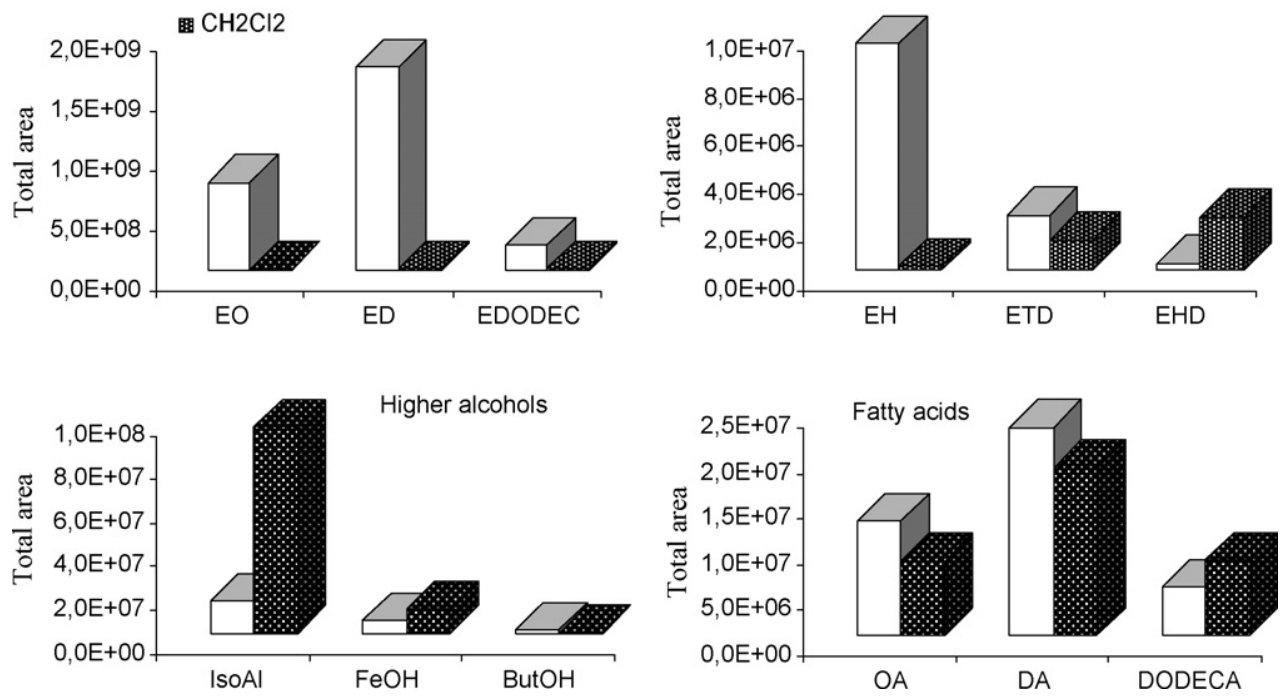

Fig. 4. Proportion of the chromatographic profile between $\mathrm{LLE}_{\mathrm{CH}_{2} \mathrm{Cl}_{2}}$ and $\mathrm{SPME}_{\mathrm{CAR} / \mathrm{PDMS}}$ methods for analysis of different chemical classes and specific compounds determined in BL whiskey (DCM: $\mathrm{CH}_{2} \mathrm{Cl}_{2}$; EO: ethyl octaoate; ED: ethyl decanoate; EDODEC: ethyl dodecanoate; EH: ethyl hexanoate; ETD: ethyl tetradecanoate; EHD: ethyl hexadecanoate; OA: octanoic acid; DA: decanoic acid; DODECA: dodecanoic acid; IsoAl: 3-methylbutan-1-ol; FeOH: $\beta$-phenylethanol; ButOH: butan-1-ol).

1.000 (propan-1-ol, isoamyl acetate, ethyl butanoate and ethyl decanoate) for $\mathrm{LLE}_{\mathrm{CH}_{2} \mathrm{Cl}_{2}}$ (Table 1) and between 0.9935 ( $\beta$ phenoxyethanol) and 1.000 (ethyl octanoate, octanoic acid) for

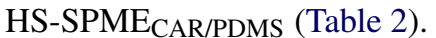

The precision was studied as reproducibility and expressed as relative standard deviation, (R.S.D.) for BL whiskey which was extracted six times and injected in triplicate. Percent R.S.D. values range from $3.19 \%$ (2-methylpropan-1-ol) to $19.42 \%$ (decanoic acid) for the $\mathrm{LLE}_{\mathrm{CH}_{2} \mathrm{Cl}_{2}}$ (Table 1) and between $3.97 \%$ (ethyl hexanoate) and $14.78 \%$ (octanoic acid), for HSSPME PDMS method (Table 2).
The accuracy of both the analytical methods was evaluated from the determination of the recovery, obtained by the addition of known quantities of the target compounds in a commercial BL whiskey. No significant differences were found between them at a significance level of 5\%. Recoveries near $100 \%$ were obtained for all the volatile compounds under study.

The values obtained for detection and quantification limits (Tables 1 and 2), are in general, low enough to permit the determination of these compounds in whiskey samples. The values obtained by SPME $E_{\text {CAR/PDMS }}$ were much lower than the values determined by $\mathrm{LLE}_{\mathrm{CH}_{2} \mathrm{Cl}_{2}}$.

Table 4

Odour description, odour threshold and odour activity values of the main odour-active compounds of commercial whiskeys

\begin{tabular}{|c|c|c|c|c|c|c|c|c|c|c|}
\hline \multirow[t]{2}{*}{ Compound } & \multirow[t]{2}{*}{ Odour description } & \multirow{2}{*}{$\begin{array}{l}\text { Odour threshold } \\
\left(\mu \mathrm{gL}^{-1}\right)\end{array}$} & \multicolumn{8}{|l|}{$\mathrm{OAV}^{\mathrm{a}}$} \\
\hline & & & $\mathrm{HC}$ & FG & DW & RL & BL & GRA & $\mathrm{JL}$ & BAL \\
\hline Butan-1-ol & Pungent, harsh & $150000^{c}$ & 0.62 & 1.30 & 0.87 & 0.66 & 3.01 & 0.12 & $<0.1$ & 0.45 \\
\hline 2-Methtylpropan-1-ol & Wine, solvent & $40000^{\mathrm{b}}$ & 55.53 & 64.10 & 66.42 & 57.76 & 75.26 & 65.32 & 60.46 & 57.65 \\
\hline Isoamyl acetate & Banana & $30^{\mathrm{b}}$ & 150.35 & 125.43 & 121.35 & 92.72 & 100.21 & 190.51 & 128.27 & 127.61 \\
\hline 3-Methylbutan-1-ol & Sweet, fusel & $30000^{\mathrm{b}}$ & 3.25 & 3.81 & 3.89 & 3.90 & 5.57 & 4.49 & 2.60 & 3.81 \\
\hline Furfural & Fruity, floral & $20000^{\mathrm{d}}$ & 0.27 & 1.08 & 0.66 & 0.72 & 2.66 & 0.79 & 0.06 & 0.71 \\
\hline Ethyl decanoate & Floral, soap & $200^{c}$ & 26.56 & 50.13 & 42.15 & 39.14 & 45.36 & 49.61 & 20.09 & 37.53 \\
\hline$\beta$-Phenylethanol & Floral, rose, honey & $14000^{c}$ & 0.19 & 0.16 & 0.14 & 0.18 & 0.20 & 0.32 & $<0.1$ & 0.20 \\
\hline Ethyl dodecanoate & fruity, floral & $1200^{\mathrm{c}}$ & 3.47 & 6.73 & 2.97 & 4.86 & 4.71 & 4.37 & 3.39 & 4.69 \\
\hline Hexanoic acid & Sweety, cheesy & $420^{c}$ & 4.83 & 5.31 & 6.60 & 6.12 & 7.40 & 6.42 & 4.21 & 6.17 \\
\hline Octanoic acid & Cheese & $500^{c}$ & 8.93 & 13.85 & 19.56 & 17.22 & 23.37 & 19.99 & 6.48 & 18.11 \\
\hline
\end{tabular}

a Odour activity value calculated by dividing concentration by odour threshold value of the compound. In bold compounds with OAV $<1$.

${ }^{b}$ Guth [43]. The matrix was a $10 \%$ water/ethanol solution.

${ }^{c}$ Ferreira et al. [44]. The matrix was a $11 \%$ water/ethanol solution containing $7 \mathrm{~g} \mathrm{~L}^{-1}$ of glycerol and $5 \mathrm{~g} \mathrm{~L}^{-1}$ of tartaric acid, with the $\mathrm{pH}$ adjusted to 3.4 with $1 \mathrm{M} \mathrm{NaOH}$

${ }^{\mathrm{d}}$ Boidron et al. [45]. The matrix was a synthetic wine containing $12 \%$ ethanol, $8 \mathrm{~g} \mathrm{~L}^{-1}$ of glycerol and different salts. 


\subsection{Volatile compounds in commercial whiskeys}

The R.S.D. values for triplicate samples were $<10 \%$. 3Methylbutan-1-ol is the main component in all whiskeys volatile fractions, followed by decanoic acid and ethyl decanoate. It was observed that the total average concentration of volatile constituents in BL whiskeys are of $262.65 \mathrm{mg} \mathrm{L}^{-1}$ while for the other commercial whiskeys, the average concentration are significantly lower $(p<0.05,95 \%)$. The higher alcohols are the chemical family that contributes for this significant difference, from which 3-metilbutan-1-ol and 2-methylpentan1-ol are highlighted. Our results, using both $\mathrm{LLE}_{\mathrm{CH}_{2} \mathrm{Cl}_{2}}$ and SPME $E_{C A R / P D M S}$ methods, indicate that $\mathrm{BL}$ has significantly elevated levels of higher alcohols and furanic compounds as compared to JL and HC whiskeys. Levels of higher alcohol acetates and fatty acids are significantly lower in RL and FG whiskeys, respectively.

\subsection{Comparison of the two analytical methods}

The conventional LLE method and the new HS-SPME methodology were applied to the analysis of nine commercial whiskey samples in order to determine the volatile profile and to compare the different samples. The instrumental analytical conditions chosen allow the separation of the all compounds studied. Relative peak area counts (RPA) and relative standard deviation (R.S.D.) of volatile compounds detected in whiskey using LLE and SPME, together with their calculated Kovàts indices are shown in Table 3 in order of elution. As can be seen from the data, 65 volatile organic compounds were tentatively identified in whiskey extracts using the SPME $E_{C A R / P D M S}$ technique and 61 by $\mathrm{SPME}_{\mathrm{CW} / \mathrm{DVB}}$, whereas 55 compounds were positively identified by $\mathrm{LLE}_{\mathrm{CH}_{2} \mathrm{Cl}_{2}}$.

Basically, volatile flavour compounds comprised: ethyl esters (17 SPME and $14 \mathrm{CH}_{2} \mathrm{Cl}_{2}$ ), higher alcohols (16 SPME and $8 \mathrm{CH}_{2} \mathrm{Cl}_{2}$ ), higher alcohol acetate (3 SPME and $2 \mathrm{CH}_{2} \mathrm{Cl}_{2}$ ), isoamyl acetates (4 SPME and $1 \mathrm{CH}_{2} \mathrm{Cl}_{2}$ ), fatty acids (4 SPME

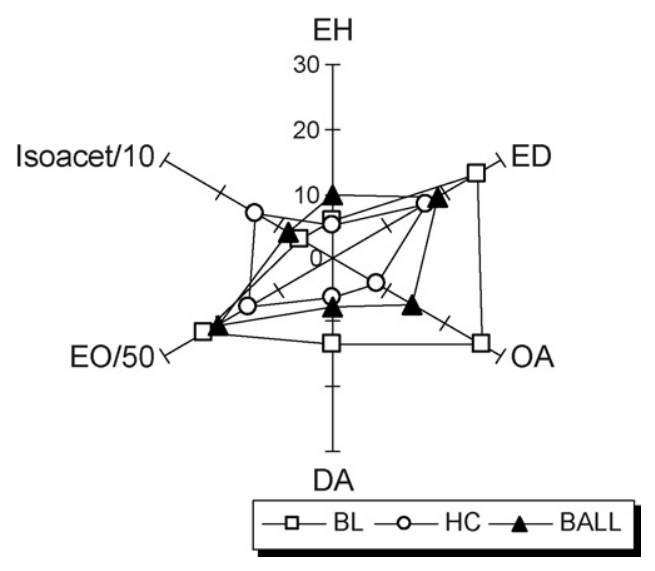

Fig. 5. Main odorants found in BL, HC and RL whiskeys determined by HS-

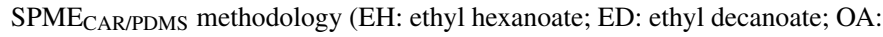
octanoic acid; DA: decanoic acid; EO/50: ethyl octanoate concentration divided by 50; Isoacet: 3 -methylbutan-1-ol acetate concentration divided by 10 ).

and $9 \mathrm{CH}_{2} \mathrm{Cl}_{2}$ ), carbonyl compounds (3 SPME and $7 \mathrm{CH}_{2} \mathrm{Cl}_{2}$ ), hydrocarbons ( $9 \mathrm{SPME}$ and $4 \mathrm{CH}_{2} \mathrm{Cl}_{2}$ ), monoterpenes and $\mathrm{C}_{13}$ norisoprenoids (8 SPME and $2 \mathrm{CH}_{2} \mathrm{Cl}_{2}$ ) and volatile phenols (4 SPME and $6 \mathrm{CH}_{2} \mathrm{Cl}_{2}$ ). Typical GC-ITDMS chromatographic profile of the volatile fraction isolated from $\mathrm{BL}$ whiskey by LLE $_{\mathrm{CH}_{2} \mathrm{Cl}_{2}}$, HS-SPME ods, are shown in Fig. 3. Table 3 displays the semi-quantitative results of the volatile organic components derived from triplicate extractions.

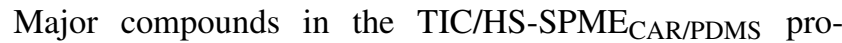
file were ethyl esters $\left(\mathrm{C}_{10} \gg \mathrm{C}_{8}>\mathrm{C}_{12}\right.$, and in lower content $\mathrm{C}_{14}>\mathrm{C}_{16}$ ), higher alcohols (3-methylbutan-1-ol $>\beta$ phenylethanol) and fatty acids $\left(\mathrm{C}_{10}>\mathrm{C}_{8}>\mathrm{C}_{12}\right)$, while in the TIC/LLE $\mathrm{CH}_{2} \mathrm{Cl}_{2}$ profile, higher alcohols (3-methylbutan-1-ol > $\beta$-phenylethanol), ethyl esters $\left(\mathrm{C}_{10}>\mathrm{C}_{12}>\mathrm{C}_{8}\right)$, 5-hydroxymethylfurfural and vanillin are the major ones. This suggests that SPME is generally a more sensitive technique than LLE for the extraction of aroma compounds from whiskey, although in practice the two methods may complement each other.
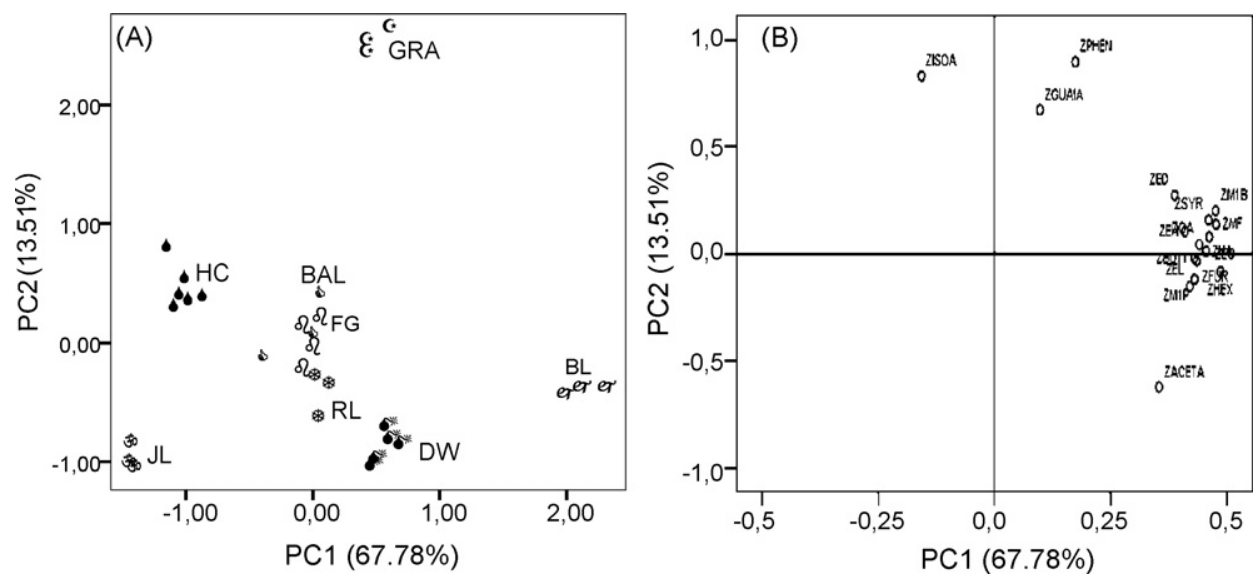

Fig. 6. PC1 vs. PC2 scatter plot of the main sources of variability between different whiskeys: (A) distinction between the samples (scores) and (B) relation between the 22 volatile compounds (loading). Identification of the variables: M1P: 2-Methylpropan-1-ol; BUT: butan-1-ol; M1B: 3-methylbutan-1-ol; HEX: hexan-1-ol; PHEN: 2-phenylethanol; ISOA: isoamyl acetate; EH: ethyl hexanoate; EL: ethyl lactate; EO: ethyl octanoate; ED: ethyl decanoate; HA: hexanoic acid; OA: octanoic acid; ACET: acetaldehyde; SYR: syringaldehyde; FUR: 2-furfural; MF: 5-methyl-2-furfural; GUA: guaiacol. 
Differences in the selectivity between each extraction method were observed. In general, $\mathrm{LLE}_{\mathrm{CH}_{2} \mathrm{Cl}_{2}}$ extracted higher alcohols more efficiently than HS-SPME $\mathrm{CAR}_{\mathrm{C} / \mathrm{PDMS}}$. However, this methodology was more selective for ethyl esters and fatty acids than was $\mathrm{LLE}_{\mathrm{CH}_{2} \mathrm{Cl}_{2}}$. The major compounds appeared to be the same as those in $\mathrm{CH}_{2} \mathrm{Cl}_{2}$ extracts. As can be seen, the values obtained for these compounds by $\mathrm{SPME}_{\mathrm{CAR} / \mathrm{PDMS}}$ differed to those obtained by $\mathrm{LLE}_{\mathrm{CH}_{2} \mathrm{Cl}_{2}}$. Fig. 4 shows the proportion of some of volatile compounds identified in whiskey samples by both SPME ${ }_{\mathrm{CAR} / \mathrm{PDMS}}$ and $\mathrm{LLE}_{\mathrm{CH}_{2} \mathrm{Cl}_{2}}$ methods.

\subsection{Identification of the main odorants}

To estimate the sensory contribution of the volatiles to the overall flavour of whiskeys the OAV values were calculated. Aroma-active compounds detected in whiskeys and their aroma properties are given in Table 4. However, the ranking of the $\mathrm{OAV}$ values were different because of differences in concentration levels. From all volatile quantified compounds, those present at concentrations higher than their odour threshold are mainly considered as aroma contributing substances. The results showed that, 14 out of 25 components (56\%) quantified in the studied commercial whiskeys were found at concentrations higher than their corresponding threshold values $(\mathrm{OAVs} \geq 1)$. According to the OAV values, ethyl octanoate, a compound associated with sweet, fruity and fresh notes, was the most intense odorant in the studied samples (Fig. 5). Isoamyl acetate was the next most significant compound with an OAV values that ranges from 92.72 (RL) to 190.52 (GRA). This compound contributed for the total aroma of the whiskeys, with a characteristic banana-like odour. With regard to alcohols, 3-methylbutan-1-ol (fruity) and 2-methylpropan-1-ol (bitter, harsh), were the only ones found contributing to whiskey aroma. Butan-1-ol and $\beta$ phenylethanol, although exhibiting OAV values lower than 1 also could contribute to the floral character of studied whiskeys, due to the synergic effects in the matrix. Ethyl hexanoate showing a green apple and anise aroma, was identified as another important aroma-active compounds in $\mathrm{DW}>\mathrm{BL}>\mathrm{GRA}>\mathrm{FG}>\mathrm{BAL}$ whiskeys. In $\mathrm{HC}$, RL and LJ samples, this compound present $\mathrm{OAV}$ values lower than 0.1 , and do not contribute to the aroma of these whiskeys. Hexanoic, octanoic and decanoic acids exhibit an aroma index very high, indicating that these compounds probably can contribute individually to the studied whiskeys aroma.

There is a similarity in the OAV values between the different commercial whiskey samples. The most significant differences were observed for BL and GRA (Fig. 5). The highest OAV values were gotten for by-products of the fermentative metabolism, such as: ethyl octanoate, isoamyl acetate, ethyl decanoate and 2-methylpropan-1-ol. The volatile compounds that contribute less for the aromatic profile are butan-1-ol, furfural and $\beta$ phenylethanol.

\subsection{Whiskey differentiation}

The proposed $\mathrm{LLE}_{\mathrm{CH}_{2} \mathrm{Cl}_{2}}$ method was applied to nine different commercial whiskeys. Evidently, the different concentrations of the volatile constituents determined in these samples allow their differentiation. The obtained results were subjected to principal components analysis (PCA) which revealed that GRA, HC, LJ, and BL whiskeys were clearly separated in a twodimensional projection. The PCA results show that $81.29 \%$ for the obtained results can be represented in a subspace formed by two coordinates (principal components) constructed from linear combinations of the various concentrations that describe each volatile fraction. Fig. 6 shows how GRA whiskey is clearly separated from the others. From the latest, $\mathrm{LJ}$ and BL are the most differentiated ones, followed by HC and DW. The BAL, FG and RL whiskeys were too closed that confirm that they have very similar compositions. The compounds which contributed most to the differentiation were hexan-1-ol, 3-methylbutanoic acid and $\beta$-phenylethanol.

Factor 1 which explains $67.78 \%$ of the information is constructed mainly from contribution of hexan-1-ol (0.97), 3methylbutanoic acid (0.97), 3-methylbutan-1-ol acid (0.96) and 5 -methylfurfural (0.96). Factor 2 correspond to $13.5 \%$ of the information and consist mainly of $\beta$-phenylethanol (0.96) and isoamyl acetate (0.90).

\section{Conclusions}

For a complete and quantitative study of volatile composition in food beverages, two or more sample preparation techniques are recommended. Volatile compounds of whiskeys extracted using the two methods LLE and SPME were identified by GC-MS. Twenty-five of them were quantified by GC-FID, and their odour-active compounds identified. HS-SPME CAR/PDMS $_{\text {S }}$ provides a more sensitive technique to the traditional method of LLE. Sixty-five volatile organic compounds were identified using HS-SPME $E_{C A R / P D M S}$ applied to the extraction of BL whiskey, whereas only 55 aroma compounds were identified using traditional LLE. The main advantages of LLE compared to other conventional methods are that is simple, rapid and no specific instrumentation was required. The $\mathrm{LLE}_{\mathrm{CH}_{2} \mathrm{Cl}_{2}-\mathrm{GC}-\mathrm{FID}}$ analysis revealed that volatile fractions of the studied whiskeys were very rich in ethyl esters followed by higher alcohols and fatty acids.

HS-SPME method using CAR/PDMS coating fibre followed by GC and MS detector is a good procedure for the analysis of several whiskey flavour compounds. The study has revealed potent odorants that are responsible for the overall flavour of the investigated whiskeys. Ethyl octanoate followed by isoamyl acetate, 2-methylpropan-1-ol, ethyl decanoate and decanoic acid, were identified as the main odour-active compounds, on the basis of their high OAV values.

The identification of whiskey aroma compounds and the determination of analytical ratio combined with statistics provide efficient tools like: differentiation of whiskies, establishing criteria for genuineness, improvement of quality, prevention of frauds and guaranteeing their origin.

\section{Acknowledgments}

The authors are grateful to the Famous Grouse Company (Scotland) and Prime Drinks, Lda. (Portugal) for supply of the samples used in this study. 


\section{References}

[1] G. Fitzgerald, K.J. James, K. MacNamara, M.A. Stack, J. Chromatogr. A 896 (2000) 351.

[2] W. Wardencki, P. Sowinski, J. Curylo, J. Chromatogr. A 984 (2003) 89.

[3] S.E. Ebeler, M.B. Terrien, C.E. Butzke, J. Sci. Food Agric. 80 (2000) 625.

[4] D. González-Arajona, V. Goazález-Gallero, F. Pablos, A.G. González, Anal. Chim. Acta 381 (1999) 257.

[5] K.Y. Mónica Lee, A. Paterson, J.R. Piggott, G.D. Richardson, Food Qual. Prefer. 12 (2001) 109

[6] R. López, M. Aznar, J. Cacho, V. Ferreira, J. Chromatogr. A 966 (2002) 166.

[7] V. Ferreira, R. López, J. Cacho, J. Sci. Food Agric. 80 (2000) 1659.

[8] V. Ferreira, N. Ortin, A. Escudero, R. Lopez, J. Cacho, J. Agri. Food Chem. 50 (2002) 4048.

[9] J.M. Nuñez, H. Bemelmans, J. Chromatogr. A 294 (1984) 361.

[10] G.P. Blanch, G. Reglero, M. Herraiz, J. Agric. Food Chem. 43 (1995) 1251.

[11] A. Razungles, H. Tarhi, R. Baumes, C. Günata, C. Tapiero, C. Bayonnove, Sci. Aliment. 14 (1993) 59.

[12] C. Cocito, G. Gaetano, C. Delfini, Food Chem. 52 (1995) 311.

[13] C. Arthur, J. Pawlizyn, Anal. Chem. 62 (1990) 2145.

[14] H.L. Lord, J. Pawlizyn, Anal. Chem. 69 (1997) 3899.

[15] C. Arthur, L. Killam, K. Buchholz, J. Pawlizyn, J. Berg, Anal. Chem. 64 (1992) 1960.

[16] J.S. Câmara, P. Herbert, J.C. Marques, M.A. Alves, Anal. Chim. Acta 513 (2004) 203.

[17] S.M. Rocha, L. Maeztu, A. Barros, C. Cid, M.A. Coimbra, J. Sci. Food Agric. 84 (2003) 43.

[18] J.J. Rodriguez-Bencomo, J.E. Conde, M.A. Rodriguez-Delgado, F. GarciaMontelongo, J.P. Pérez-trujillo, J. Chromatogr. A 963 (2002) 213.

[19] J.S. Câmara, M.A. Alves, J.C. Marques, Anal. Chim. Acta 555 (2006) 191.

[20] S.M. Rocha, P. Coutinho, A. Barros, I. Delgadillo, M.A. Coimbra, J. Chromatogr. A 1114 (2006) 188.

[21] E. Coelho, S.M. Rocha, I. Delgadillo, M.A. Coimbra, Anal. Chim. Acta 563 (2006) 204.

[22] J.J. Rodriguez-Bencomo, J.E. Conde, F. Garcia-Montelongo, J.P. PérezTrujillo, J. Chromatogr. A 991 (2003) 13.
[23] S.M. Rocha, F. Rodrigues, P. Coutinho, I. Delgadilho, M.A. Coimbra, Anal. Chim. Acta 513 (2001) 257.

[24] T.A. Ternes, Water Res. 32 (1998) 3245

[25] M. Moeder, S. Schrader, M. Winkler, P. Popp, J. Chromatogr. A 873 (2000) 95.

[26] H. Kataoka, H.L. Lord, J. Pawliszyn, J. Chromatogr. A 880 (2000) 35.

[27] J.S. Câmara, M.A. Alves, J.C. Marques, Talanta 68 (2006) 1512.

[28] M.A. Pozo-Bayón, E. Pueyo, P.J. Martín-Álvarez, M.C. Polo, J. Chromatogr. A 922 (2001) 267.

[29] L.M.T.V. Freire, A.M.C. Freitas, A.M. Relva, J. Microcol. Separ. 13 (2001) 236

[30] L. Mondello, R. Costa, P.Q. Tranchida, P. Dugo, M. Lo Presti, S. Festa, A. Fazio, G. Dugo, J. Separ. Sci. 28 (2005) 1101.

[31] L. Lecanu, V. Ducruet, C. Jouquand, J.J. Gratadoux, A. Feigenbaun, J. Agric. Food Chem. 50 (2002) 3810.

[32] C. Deng, N. Li, X. Zhang, J. Chromatogr. B 808 (2004) 269.

[33] C. Deng, X. Zhang, N. Li, J. Chromatogr. B 813 (2004) 47.

[34] E. Baltussen, P. Sandra, F. David, C. Cramers, J. Microcol. Separ. 11 (1999) 737

[35] D.J.C. Quantrill, A.J. Buglass, J. Chromatogr. A 1117 (2006) 121.

[36] A. Zalacain, J. Marín, G.L. Alonso, M.R. Salinas, Talanta 71 (2007) 1610.

[37] J.C.R. Demyttenaere, J.I.S. Martinez, R. Verhé, P. Sandra, N. De Kimpe, J. Chromatogr. A 985 (2003) 221.

[38] R.F. Alves, A. Nascimento, J.M. Nogueira, Anal. Chim. Acta 546 (2005) 11.

[39] R. Perestrelo, A. Fernandes, F.F. Albuquerque, J.C. Marques, J.S. Câmara, Anal. Chim. Acta 563 (2006) 154.

[40] H. van den Dool, P.D. Kratz, J. Chromatogr. 11 (1963) 463.

[41] J.S. Câmara, J.C. Marques, R.M. Perestrelo, F. Rodrigues, L. Oliveira, P Andrade, M. Caldeira, J. Chromatogr. A 1150 (2007) 198.

[42] Eight Peak Index of Mass Spectra, 2nd ed., The Mass Spectra Data Centre, Nottighan, UK, 1974.

[43] H. Guth, J. Agric. Food Chem. 45 (1997) 3027.

[44] V. Ferreira, R. López, J.F. Cacho, J. Sci. Food Agric. 80 (2000) 1659.

[45] J.N. Boidron, P. Chatonnet, M. Pons, Connaissance Vigne Vin 22 (1988) 275 . 